\title{
NEW PROCEEDINGS SYSTEM
}

Starting with the November 1984 Annual Meeting, the Materials Research Society will be its own publisher of the Symposium PROCEEDINGS volumes. As a result, prices of the volumes should be significantly reduced, while the format and quality remains consistent with previous editions.

Directing this extensive new publishing operation will be John Ballance, MRS Executive Director. John's previous experience as Editor of the Journal of Metals and Director of Publications for The Metallurgical Society qualifies him for this challenge.

\section{The Decision to Publish}

The decision to launch this venture was made in May by the Society's Executive Committee, following the recommendation of the Publications Committee, chaired by John Baglin. The Committee had obtained detailed bids from several recognized technical publishers, as well as a prospectus that Ballance had been asked to prepare, to be considered in competition with the proposal of Elsevier Science Publishing Company for contract renewal. A primary concern was to be able to price the volumes to MRS members reasonably. Many other factors, however, also were weighed. The Committee wanted to assure that PROCEEDINGS volumes would be distributed as widely as possible, internationally as well as in the United States. Timeliness and flexibility of publication was also a factor. The quality and style of the present series was to be maintained.

\section{Alternatives Considered}

In broader terms, the Publications Committee also explored the issue of whether the PROCEEDINGS series should retain its present form and identity, or whether some alternative form was preferable. Among the alternatives studied was adopting the format of a massive "journal," or dispersing the material among specialty publishers in the various constituent disciplines. In the end, the Committee concluded-and the Society concurred-that the present series of volumes serves the materials community well. For many professionals, a PROCEEDINGS volume is the compendium of current information on a topic, collected neatly between two covers rather than strewn through a stack of journals. Over the years, the books become the record of development in an entire field (such as beam annealing), increasing their archival value in a way many technical volumes do not. In some areas, the Society's PROCEEDINGS become an important source-work for a newly emerging field or the specialized topic that brought the original symposium together. The result is a decision to retain the present format, increase editorial and financial control through official publication, and strive to improve the content and topicality of the series.

[The Society suggests, incidentally, a standard reference format: “Mat. Res. Soc. Symp. Proc. 55193 (1985)."]

\section{A Revolutionary Principle}

Rapid publication has been a matter of keenest concern, for authors and readers alike, in connection with the PROCEEDINGS. This can best be achieved (often with significant cost savings) through an "appointments" schedule with printers that guarantees a manuscript will arrive on a certain date. Both authors and editors, therefore, are asked to recognize a revolutionary principle-real deadlines! The Society's commitment to timeliness and cost effectiveness-which translates into prompt publication and distribution-will impose a not unreasonable discipline upon contributors. Programs are in place to facilitate this development, including a new camera-ready format authors will use, and complete instructions are being prepared. The new systems should help ensure that manuscripts require minimal mechanical editing, and thus speed the preparation of the assembled volume.

\section{A Pleasant Surprise}

The Finance Committee, under the direction of Clyde Northrup, has done detailed four-year projections of the viability of the new enterprise, and concurs that it is sound, practical, and advantageous. The Materials Research Society expects the venture to contribute to its financial stability at a pricing level members will find a pleasant surprise. It also should contribute to the Society's independence and its stature. Most importantly, it will improve communication among materials professionals, and thus better serve our members and our scientific community.

\section{MIRIS BULLETIN}

VOLUME IX

NUMBER 3

The Materials Research Society BULLETIN is published bi-monthly by the Materials Research Society for its members and others interested in materials science. Correspondence and submissions are invited. They should be brief and typewritten (double-spaced) and the author's affiliation must be indicated. Address all material to the Editor.

President C.W. WHITE Oak Ridge National Laboratory Vice President E.N. KAUFMANN Lawrence Livermore National Laboratory

Vice President B.R. APPLETON Oak Ridge National Laboratory Secretary R.L. SCHWOEBEL Sandia National Laboratories

Treasurer K.C. TAYLOR GM Research Laboratories

Past President H.J. LEAMY AT\&T Bell Laboratories

Executive Director J.B. BALLANCE Materials Research Society, 9800 McKnight Road, Suite 327, Pittsburgh, PA 15237. (412) $367-3003$

Editor T.G. MIDDLETON P.O. Box $K$, Short Hills, NJ 07078, (201) 467-0504 